\title{
BASIC TECHNICAL SKILLS (THROWS) IN 17-19-YEAR-OLD JUDOKAS
}

Jagiełło Władysław, Dornowski Marcin, Wolska Beata

Gdansk University of Physical Education and Sport in Gdansk, Department of Sport

\begin{abstract}
Annotation. Purpose: The purpose of the research was to determine basic technical skills (throws) in 17-19-year-old judokas and the level of their performance. Material: The study involved 30 judo athletes (aged 17-19). Results: To determine the athletes' basic technical skills (throws), an analysis of source materials and a diagnostic survey were used. To determine the level of technical skills, the method of expert assessment was applied. Statistical software package Statistica 8 was used in the statistical analysis. In the coaches' opinion, 17-19-year-old judokas have a specific, characteristic of this age group, set of basic technical skills (throws) aptly defining their technical preparation. Conclusions: The tested group of judokas exhibited the highest level of demonstrating throws of the koshi-waza (hip) group, and the lowest one of the ashi-waza (foot) group.
\end{abstract}

Keywords: judo, skills, technique, throws.

\section{Introduction}

In the modern depiction of the basic theory of combat sports [9] the notion of technique has been explained in many ways. The combat technique, corresponding with sports technique, is the entirety of resources and skills that allow performing any action falling within the scope of human activity. For the needs of the theory and practice of martial arts, the combat technique has been defined as "such a sports technique used which, due to the assimilated motor habits, facilitates achieving the objectives of the fight, or else it is a use of such an even unpractised before motor solution that the fighting person believes to be the best at any given moment" [9].

Judo techniques as the entirety of skills have been divided into three groups $[10,11]$ : nage-waza - throwing $(67$ techniques), katame-waza - grappling (29 techniques), atemi-waza - striking at vital points of the body (24 techniques).

Throws (nage-waza) are divided into those performed in a standing position (tachi-waza) and those during which the athlete loses his balance himself (sutemi-waza). Depending on the involvement of various parts of the body in the performed technique, tachi-waza are divided into: hand (te-waza) - 15 throws; hip (koshi-waza) - 11 throws; foot (ashiwaza) -21 throws.

Sacrifice throws (sutemi-waza) are two groups of techniques: with the fall on one's back (ma-sutemi-waza -5 throws) and falling on one's side (yoko-sutemi-waza - 15 throws).

Many scientists $[2,4,5,12,13,15]$ researched technical preparation of athletes practicing judo. However, the question of what arsenal of techniques an athlete should master at each stage of training is still open.

With this in view, the aim of the study was to determine basic technical skills (throws) in 17-19-year-old judokas and getting to know the level of their performance.

\section{Research material and methods}

The results of measurements from the years 2006-2008 carried out in the Laboratory of Physical Effort at Gdańsk University of Physical Education and Sport in Gdańsk were used in the research. The Bioethics Commission at the Regional Medical Chamber in Gdansk accepted information on the research without objections. The study does not have hallmarks of a medical experiment on a human being.

30 athletes practicing judo (aged 17-19) participated in the study. These were pupils of the Comprehensive Sports Secondary Schools Complex from judo classes and athletes training in clubs of the Pomeranian and the Warmian-Masurian Voivodeships. The examined judokas' age, on average, amounted to $17.83 \pm 0.64$ years, while their body weight to $69.66 \pm 12.33 \mathrm{~kg}$.

On average, the subjects had trained judo for $7.05 \pm 2.46$ years. 4 athletes had the first sports class, 12 athletes the second one, and 14 the third one. Two judokas were members of the national team of younger juniors; 8 athletes were members of the juniors team of the voivodeship.

To determine the basic technical skills (throws) for judo athletes at the age of 17-19 years, an analysis of source materials (research reports and the Olympic Games and the World Championships protocols) were used as well as a diagnostic survey using a questionnaire, which was completed by 30 judo coaches of the championship and the first class.

To determine the level of technical skills, the method of expert assessment was used. Each technique (throw), indicated by the coaches in the previously carried out diagnostic survey, was assessed on a scale of 1-10 (divided into tenths of a point). Every mistake and failure to comply with the model had adequate point penalties as referred to in a specially prepared evaluation protocol. Three experts assessed the conformity of the demonstrated skills (throws from four groups) with the model. The task of each subject was to demonstrate with his partner (equal in terms of height and weight) of all the indicated throws from the right-hand posture. All the experts' evaluations were then averaged.

Basic indices of the software package Statistica 8 were applied in statistical analysis. 
Research results

On the basis of the judo coaches' opinions and an analysis of the source materials, a set of technical skills (throws) in four groups was developed, which subsequently were subjected to evaluation of the level of their performance.

In the group of hand throws (te-waza) the subjects obtained the lowest value of the performance level in the uchi-mata-sukashi throw -7.95 point $(79.5 \%)$ with the spread of results 5.7 , and the highest one in ippon-seoi-nage 9.45 points $(94.5 \%)$ with the spread of results 3.2 (Tab. 1$)$.

The subjects obtained the lowest value in the Ashi-waza group in the sasae-tsurikomi-ashi throw -7.82 points $(78.2 \%)$ with the spread of results of 4.8 , and the highest one in the osoto-gari throw 9.35 point $(93.5 \%)$ with the spread of results 3.9 .

In assessing the level of performance of hip throws Koshi-waza, the lowest average arithmetic mean in the group was achieved by the subjects in the utsuri goshi throw -7.89 points $(78.9 \%)$ with the spread of results of 3.6, and the highest one in the o-goshi throw 9.8 points $(98 \%)$ with the spread of results of 3.1 .

The subjects achieved the lowest value in the group of sacrifice throws Masutemi-waza, Yoko-sutemi-waza in the yoko-guruma throw -7.85 points $(78.5 \%)$ with the spread of results of 5.3, and the highest one in tomoe-nage - 9.1 points $(91 \%)$ with the spread of results of 5.1 .

Table 1.

Basic technical skills (throws) in 17-19-year-old judokas and the level of their performance (points).

\begin{tabular}{|c|c|c|c|c|c|c|c|}
\hline \multicolumn{2}{|c|}{ Te-waza } & \multicolumn{2}{|c|}{ Ashi-waza } & \multicolumn{2}{|c|}{ Koshi-waza } & \multicolumn{2}{|c|}{$\begin{array}{c}\text { Ma-sutemi-waza, Yoko- } \\
\text { sutemi-waza }\end{array}$} \\
\hline Throws & $\begin{array}{c}\text { Level, } \\
\text { pts. }\end{array}$ & Throws & $\begin{array}{l}\text { Level, } \\
\text { pts. }\end{array}$ & Throws & $\begin{array}{l}\text { Level, } \\
\text { pts }\end{array}$ & Throws & $\begin{array}{l}\text { Level, } \\
\text { pts. }\end{array}$ \\
\hline $\begin{array}{c}\text { IPPON-SEOI- } \\
\text { NAGE }\end{array}$ & 9,45 & OSOTO-GARI & 9,35 & O-GOSHI & 9,8 & TOMOE-NAGE & 9,1 \\
\hline SUKUI-NAGE & 9,25 & UCHI-MATA & 8,95 & KOSHI-GURUMA & 9,65 & SUMI-GAESHI & 9 \\
\hline SEOI-NAGE & 9,15 & OUCHI-GARI & 8,95 & HARAI-GOSHI & 9,2 & $\begin{array}{c}\text { OSOTO } \\
\text { MAKIKOMI }\end{array}$ & 8,9 \\
\hline $\begin{array}{l}\text { KUCHIKI- } \\
\text { TAOSHI }\end{array}$ & 9,05 & DEASHI-HARAI & 8,75 & USHIRO-GOSHI & 8,95 & $\begin{array}{c}\text { SOTO } \\
\text { MAKIKOMI }\end{array}$ & 8,8 \\
\hline $\begin{array}{l}\text { KIBISU- } \\
\text { GAESHI }\end{array}$ & 8,7 & KOSOTO-GARI & 8,6 & HANE-GOSHI & 8,95 & YOKO GAKE & 8,7 \\
\hline TAI-OTOSHI & 8,7 & $\begin{array}{l}\text { OKURI-ASHI- } \\
\text { HARAI }\end{array}$ & 8,55 & $\begin{array}{l}\text { TSURIKOMI- } \\
\text { GOSHI }\end{array}$ & 8,9 & $\begin{array}{l}\text { UCHIMATA } \\
\text { MAKIKOMI }\end{array}$ & 8,65 \\
\hline $\begin{array}{l}\text { KOUCHI- } \\
\text { GAESHI }\end{array}$ & 8,65 & HIZA-GURUMA & 8,3 & $\begin{array}{c}\text { SODE- } \\
\text { TSURIKOMI- } \\
\text { GOSHI }\end{array}$ & 8,7 & URA-NAGE & 8,6 \\
\hline SEOI-OTOSHI & 8,25 & OSOTO-OTOSHI & 8,1 & UKI-GOSHI & 8,2 & TANI-OTOSHI & 8,4 \\
\hline $\begin{array}{l}\text { MOROTE- } \\
\text { GARI }\end{array}$ & 8,12 & KOUCHI-GARI & 8,01 & TSURI-GOSHI & 8,08 & YOKO OTOSHI & 8,3 \\
\hline $\begin{array}{l}\text { UCHI-MATA- } \\
\text { SUKASHI }\end{array}$ & 7,95 & $\begin{array}{c}\text { SASAE- } \\
\text { TSURIKOMI- } \\
\text { ASHI }\end{array}$ & 7,82 & UTSURI-GOSHI & 7,89 & $\begin{array}{c}\text { YOKO } \\
\text { GURUMA }\end{array}$ & 7,85 \\
\hline
\end{tabular}

\section{Discussion}

Judo is an acyclic sport, classified as a speed-strength discipline with a complex coordination structure. For this reason, a judoka's victory is determined by many factors. However, it is technical preparation that has the greatest 
contribution to obtaining high sports results. Thus, the study of the most appropriate technical preparation is a key element of judokas training at various stages of long-time sports training $[6,7]$.

The authors use a variety of ways to assess the technical skills of throws. Adam et al. [1] defined the dominant techniques (throws) during a sports fight using the number of attacks which resulted in ippon, the total number of effective attacks and the average ippon, waza ari and yuko score obtained during the fight. To determine the dominant and the most effective techniques, values of indices calculated from two formulas were used. The authors observed an increase in the quality of performance of foot throws and uki waza (different ways of performance). In the case of this study, the situation was different. The highest rating was obtained in the hip throws group Koshi-Waza - 9.8 points (ogoshi) and the lowest one in the group of foot throws Ashi-waza - 7.82 point (sasae-tsurikomi-ashi). An identical situation occurred in the case of the average result of all assessments in the groups of throws. In the group of foot throws the studied judokas obtained the lowest average results of 8.53 while in the group of hip throws -8.83 .

Franchini et al. [3] assessed technical and tactical actions during a simulated sports fight of judo using the number of attacks and the number and the type of the applied throwing techniques.

Jonczyk and Adam [8] presented a set of techniques (throws) which are the most effective in a group of winners of the Olympic Games and the World Championships. They specified the percentage of the contribution of individual groups of throws (Te-Waza 24.9\%, Sutemi-Waza 8.3\%, Koshi-Waza 5.7\%, Osae-komi-Waza 18.3\%, AshiWaza of $34.1 \%$, Shime-Waza $4.2 \%$ ) and the percentage values for individual throws.

Sadowski and Gierczuk [14] defined the level of performance of technical elements in a group of studied wrestlers using the method of objective judges' assessment - highly qualified wrestling coaches. It was based on the average of three evaluations. The extreme results (the lowest and highest ones) were rejected. The coaches evaluated technical elements using a scale from 1 to 5 points. The starting and finishing positions, the correctness of grappling, the smoothness and harmony of movement and the amplitude in the case of throws were taken into consideration.

This method of assessment of technical skills is very similar to the method used in our research. The difference only occurred in the number of objective judges (3) and the point scale (1-10).

Conclusions

Taking into account the results of the research and the practical experience, one can draw the following conclusions:

1. Judokas' technical preparation constitutes one of the most important elements of their training at different stages of long-time sports training.

2. In the coaches' opinion, 17-19-year-old judokas have a specific, characteristic of this age group, set of basic technical skills (throws) aptly defining their technical preparation.

3. The examined group of judokas demonstrated the highest level of presenting throws from the koshi-waza (hip) group, and the lowest one from the ashi-waza (foot) group.

\section{References}

1. Adam M., Smaruj M., Tyszkowki S. The diagnosis of the technical-tactical preparation of judo competitors during the World Championships (2009 and 2010) in the light of the new judo sport rules. Archives of Budo, 2011, vol.7(1), pp. 5-9.

2. Dominy E. Contest techniques and tactics. London. 1966, 200 p.

3. Franchini E., Yuri Takito M., de Moraes Bertuzzi R.C. Morphological, physiological and technical variables in high-level college judoists. Archives of Budo, 2005, vol.1, pp. 1-7.

4. Geesink A. My championship judo. London. 1966, 240 p.

5. Hoare S. The A-Z of judo. London. 2004, 244 p.

6. Jagiełło W. The long-term judo training [Długofalowy trening judoków]. Trening, 1993, vol.1(17), pp. 86-98.

7. Jagiełło W. The multi-annual training judokas [Wieloletni trening judoków]. Library Trainer. Sports Centre, Warsaw 2000, 106 p.

8. Jonczyk F., Adam M. Evolution of effectivenes of judo techniques in the opinion of the World leading judo trainers. Research Yearbook Jędrzej Śniadeci University of Physical Education, 1997, vol.4, pp. 91-96.

9. Kalina R.M. Theory of combat sports [Teoria sportów walki]. Library Trainer, Warsaw, 2000, 200 p.

10. Kano J. Kodokan Judo. Kodansha International Tokyo, New York, London. 1994, 280 p.

11. Kawamura T., Daigo T. Kodokan new Japanese-English dictionary of judo. The Fundation of Kodokan Judo Institute, Tokyo. 2000, 248 p.

12. Kobayashi K., Sharp E.H. The sport of judo as practiced in Japan. Charles E. Tuttle Co, Tokyo. 1956,160 p.

13. Koizumi G. My study of judo: the principle and the technical fundamentals. Fulsham \& Co. Ltd, London. 1960, $164 \mathrm{p}$.

14. Sadowski J., Gierczuk D. Correlations between selected coordination motor abilities and technical skills of Greco-Roman wrestlers. Archives of Budo. 2009, vol.5, pp. 36-39.

15. Sterkowicz S., Lech G. The commencement age of training and its effects on technical preferences and achievements attained by judo contestants. Human Movement. 2004, vol.5(1), pp. 42-47.

16. Sterkowicz S., Maślej P. Analysis of the fighting judo under its term structure, comparative studies [Analiza przebiegu walki judo na podstawie jej struktury czasowej, badania porównawcze]. The high-performance sport [Sport Wyczynowy]. 1999, vol.7-8, pp. 33-37. 


\section{Information about the authors:}

Jagiełło Władysław: ORCID: http://orcid.org/000-0001-5591-4537; wjagiello1@wp.pl; Gdansk University of Physical Education and Sport in Gdansk; ul. Wiejska 1, 80-336 Gdansk, Poland.

Dornowski Marcin: ORCID: http://orcid.org/0000-0002-0769-9956 mdornowski@awf.gda.pl; Gdansk University of Physical Education and Sport in Gdansk; ul. Wiejska 1, 80-336 Gdansk, Poland.

Wolska Beata: ORCID: http://orcid.org/0000-0002-6237-8645; beata wolska@wp.pl; Gdansk University of Physical Education and Sport in Gdansk; ul. Wiejska 1, 80-336 Gdansk, Poland.

Cite this article as: Jagiełło Władysław, Dornowski Marcin, Wolska Beata. Basic technical skills (throws) in 17-19-year-old judokas. Physical education of students, 2014, vol.6, pp. 77-80 doi: $10.15561 / 20755279.2014 .0615$

The electronic version of this article is the complete one and can be found online at: http://www.sportpedu.org.ua/html/arhive-e.html

This is an Open Access article distributed under the terms of the Creative Commons Attribution License, which permits unrestricted use, distribution, and reproduction in any medium. provided the original work is properly cited (http: creativecommons.org/licenses/by/3.0/deed.en).

Received: 10.06.2014

Published: 30.06 .2014 